\title{
O PRINCÍPIO DA EFICIÊNCIA ECONÔMICO-SOCIAL: UMA PROPOSTA DE VETOR DO FREE TRADE AO FAIR TRADE
}

\author{
THE SOCIAL AND ECONOMIC EFFICIENCY PRINCIPLE:
}

A VECTOR PROPOSAL FROM FREE TRADE TO FAIR TRADE

\author{
${ }^{1}$ Joana Stelzer \\ ${ }^{2}$ Daniel Rocha Chaves
}

\section{RESUMO}

A presente pesquisa avaliou a possibilidade do Princípio da Eficiência Econômico-Social (PEES) servir de matriz teórica interpretativa, no âmbito do comércio internacional, para uma desejável transição de um modelo de Free Trade para Fair Trade. O estudo considerou a diversidade fenomenológica social, especialmente sob a ótica da Análise Econômica do Direito. Além disso, foi traçado um panorama do comércio externo, apontando dificuldades e desafios. O método de pesquisa utilizado foi o hipotético-dedutivo, os estudos foram bibliográficos. Quanto aos fins, a pesquisa foi descritiva e explicativa. Os resultados foram expostos em forma de textos.

Palavras-chave: Comércio Internacional; Comércio Justo; Eficiência Econômica; Comércio Livre; Economia.

\begin{abstract}
The present research evaluated the possibility of the Social and Economic Efficiency Principle to serve as an interpretive theoretical matrix, in the scope of international trade, for a desirable transition from Free Trade to Fair Trade model. The study considered the social phenomenological diversity, especially from the point of view of the Economic Analysis of Law. In addition, a panorama of foreign trade was drawn, pointing out difficulties and challenges. The research method used was hypothetical-deductive, the studies were bibliographical. Regarding the ends, the research was descriptive and explanatory. The results were presented in the form of texts.
\end{abstract}

Keywords: International Trade; Fair Trade; Economic Efficiency; Free Trade; Economy.

\footnotetext{
${ }^{1}$ Doutora em Direito pela Universidade Federal de Santa Catarina (UFSC) Florianópolis, Santa Catarina, Brasil. Docente do Programa de Pós-Graduação em Direito (PPGD/UFSC). Pós Doutoranda na Faculdade de Direito pela Universidade de São Paulo (USP) São Paulo, Brasil. Email: contatojoana@yahoo.com.br

${ }^{2}$ Graduado em Direito pela Universidade de Fortaleza (UNIFOR), Fortaleza, Ceará. Mestrando do Programa de Pós-Graduação em Direito (PPGD/UFSC), Florianópolis, Santa Catarina, Brasil. Bolsista (CAPES/PROEX). Email: tutortreinamento@gmail.com
} 


\section{INTRODUÇÃO}

A atuação e a responsabilidade do Estado na seara do comércio internacional está fortemente alicerçada na ótica interpretativo-jurídica. O avanço do sistema multilateral, por intermédio da Organização Mundial do Comércio (OMC), deveria ter liberalizado o comércio mas, também, ter trazido o prolatado desenvolvimento econômico. $\mathrm{O}$ argumento para que esse sistema funcionasse sempre foi a eficiência econômica. O imenso prejuízo que a aplicação das teorias comerciais liberalizantes (Free Trade) trouxe aos países emergentes, contudo, exige um novo arcabouço conceitual.

Sob outra vertente, quase desconhecida nas doutrinas, está o denominado Fair Trade (Comercio Justo). Trata-se de um contramovimento ao comércio capitaneado pela OMC e que envida esforços para importar, exportar, distribuir e comercializar produtos oriundos de países em desenvolvimento (e, oportunamente, também de países desenvolvidos), no afã de alterar injustas estruturas do comércio mundial. No âmbito do Fair Trade cumpre destacar que o consumidor tem papel relevante, já que emerge como sujeito ativo da relação negocial ao exigir a sustentabilidade e a inclusão social como elementos de propulsão do sistema.

A presente investigação, sob tal pano de fundo, defronta-se com o seguinte problema: qual matriz teórica pode ser indicada para auxiliar na transição entre os sistemas de Free Trade para Fair Trade, de maneira a realizar a distribuição e redistribuição dos escassos recursos em função de uma eficiência econômico e social?

Tendo em vista tais apontamentos, o objetivo geral da presente investigação consistiu em descrever o Princípio da Eficiência Econômico-Social (PEES), enquanto vetor orientador para criação e aplicação das normas, de maneira a vislumbrar espécie de convergência entre os ideais sociais e os princípios da ordem econômica. Tendo por temática central o comércio internacional os seguintes objetivos específicos também foram perseguidos: discutir a dificuldade de valoração acerca de um critério de justiça eficiente; descrever os sistemas comerciais denominados Free Trade e Fair Trade; e, defender o Fair Trade enquanto alternativa ao comércio internacional, que tem - sob os auspícios do PEES - como principal finalidade atenuar as externalidades negativas de um sistema de troca supostamente livre.

Justifica-se o estudo, pois se entende que a prática jurídico-econômica deve ter o ser humano como meta inarredável, mesmo quando se está discutindo o comércio internacional. O critério de eficiência econômica pautado pela relação entre o valor de venda de um produto 
e seu custo de produção já não pode continuar orientando as trocas externas, embora essa tônica siga embasando a racionalidade normativa.

Entre as teorias que se apresentaram para explicar a diversidade fenomenológica social foram feitas referências a Niklas Luhmann, Richard Posner, Ronald Coase e Guido Calabresi. No âmbito da discussões sobre a eficiência, o referencial teórico teve balizamento em Ladislau Dowbor e especificamente sobre o PEES foram utilizados os estudos de Gonçalves e Stelzer (2016a). Quanto ao comércio internacional, nas propostas de Free Trade e Fair Trade, foram utilizados os sites institucionais respectivos. Relativamente ao binômio consumo e consumismo, as reflexões de Bauman, Lipovetsky e Hanna Arendt trouxeram à tona a dificuldade de mudança paradigmática no âmbito das trocas mundiais.

O método utilizado foi o hipotético-dedutivo, por se perceber que o conhecimento sobre o comércio internacional é inadequado para a contemporaneirade e que se deseja propor novo referencial. Os dados e as informações foram examinados sob forma qualitativa. Os meios de pesquisa foram exclusivamente bibliográficos, coletados por duas fontes secundárias de informação: prioritariamente, a partir de produção científica de reconhecidas obras doutrinárias; e, também, sites institucionais relativos ao assunto. Quanto aos fins, a pesquisa apresenta-se de cunho descritivo e explicativo. Os resultados foram expostos exclusivamente em forma de textos.

\section{Diversidade na análise da fenomenologia social: uma perspectiva sob a ótica da} Análise Econômica do Direito

O desmantelamento das hierarquias e estratos sociais estanques, a passagem do sistema econômico patrimonialista e feudal para o capitalismo e a diferenciação funcional dos sistemas que compõem a sociedade elevaram o nível de complexidade e contingência nos processos comunicativos inerentes à sociedade.

As observações de determinado fenômeno social podem variar de perspectiva a depender dos aportes epistemológicos que se faz valer para esse ato de conhecimento. Muitas teorias são criadas com o intuito de obter a melhor avaliação descritiva e, muitas vezes, normativa, de um fenômeno social. No âmbito das ciências jurídicas há fartura de ferramentas teóricas que analisam o Direito e sua relação com os diversos elementos inerentes à sociedade. Pode-se citar como exemplo a perspectiva política elaborada pelo jurista alemão 
Carl Schmitt (2007), a pragmática-linguística pautada no agir comunicativo de Jürgen Habermas (1997) ou a social-sistêmica desenvolvida por Niklas Luhmann (2005).

Fazendo-se valer da epistemologia social desenvolvida por Niklas Luhmann (2005), infere-se que qualquer observação da sociedade deve ser presumida, de forma antecipada e que a sociedade moderna é multicêntrica e plural, o que acarreta a inexistência de uma observação privilegiada da sociedade. Destarte, eleger alguma matriz teórica como a melhor determinação para se analisar a sociedade é uma falácia epistêmica. A partir do momento em que o observador confronta o seu objeto de estudo, segundo cabedal teórico próprio, há todo um denominado horizonte teórico que fica invisível aos olhos do cientista. Há, então, 'certa negação' das primeiras linhas da epistemologia, tendo em vista que se vai de encontro com a ideia do isolamento do eixo epistemológico. Contudo, a afirmativa da epistemologia social desenvolvida por Niklas Luhmann ressalva necessária em todos os modelos de observação da sociedade moderna, pois essa tem a hipercomplexidade como principal característica. Em verdade, a teoria nunca será a experiência real, pois, se assim o fosse, já não se estaria no campo das ideias, mas no mundo real. O que se tenta, a priori, é a aproximação de modelos de raciocínio e de esquemas ideológicos de apreciação do real. Assim, também, quanto à fenomenologia jurídica.

A partir das considerações epistemológicas sobre a observação da fenomenologia em sociedade, passa-se a trabalhar matriz teórica que vem ganhando espaço nos países de tradição jurídica romano-germânica: a Análise Econômica do Direito (AED).

É patente a conexão entre os campos do Direito e da Economia nos dois últimos séculos. A título de exemplo, podem-se citar os ensinamentos de Adam Smith e sua obra A Riqueza das Nações (1996) e a filosofia utilitarista abordada por Jeremy Bentham, no Século XIX. Tais formulações teóricas já tinham como escopo analisar a simbiose entre os efeitos econômico-sociais e as formulações normativas. Contudo, a AED foi desenvolver-se, propriamente, no Século XX, mormente, nos Estados Unidos. Richard Posner (1992, p. 21), ao traçar a história da AED, afirma que por volta de 1960 o termo Análise Econômica do Direito representava, de maneira quase equivalente, à análise do Direito Antitruste, muito embora houvesse trabalhos de natureza econômica que abordavam assuntos eminentemente jurídicos, como o Direito Tributário (Henry Simons), o Direito das Organizações e Corporações (Henry Manne) e a questão da utilidade pública e do transporte de bens comuns (Ronald Coase). 
Contudo, considera-se como sendo pioneiro trabalho que inaugurou as Escolas da Análise Econômica do Direito, propriamente dita, o artigo publicado, em 1960, no Jornal Law and Economics da Universidade de Chicago intitulado The Problem of Social Cost, de autoria de Ronald Coase. A ideia apresentada nesse trabalho é a de que a intervenção do Estado torna-se desnecessária quando os custos de transação são baixos. Para o âmbito jurídico, esse pensamento, posteriormente nomeado como Teorema de Coase, tornou-se relevante no sentido de que o Direito passou a ser funcional e consequencialista, balizando a atuação do Estado quando há falhas de mercado ou quando há elevados custos de transação.

Outro trabalho de importante relevância para o início da Análise Econômica do Direito foi Some Thoughts on Risk Distribution and the Law of Torts, de autoria de Guido Calabresi e que foi publicado no Yale Law School Journal.

Guido Calabresi foi professor de Yale e trabalhou a questão da distribuição dos riscos através do Torts Law, reconhecendo a reciprocidade de interesses quando da solução do problema das externalidades negativas geradas pela ação danosa que deveriam ser adjudicadas, pelo direito de indenização, segundo critérios de eficiência. (GONÇALVES; STELZER, 2016a, p. 265)

Com o alicerce teórico elaborado por Ronald Coase e Guido Calabresi, a AED começou a se desenvolver de forma substancial nas universidades norte-americanas, principalmente nas universidades de Chicago e Yale. Desde então, muitas vertentes, com os mais diversos suportes teóricos, foram surgindo no âmbito jurídico.

A Escola de Chicago ou Tradicional (MORDFIN; NAGORSKY, 2016) foi a pioneira na ampliação dos estudos da Análise Econômica do Direito. Nas décadas de 1960 e 1970, segundo o auspicioso 'alicerce teórico' elaborado por Ronald Coase e seus trabalhos pautados no empirismo, nos estudos sobre as firmas, bem como, na problemática do custo social, pesquisadores norte-americanos obtiveram destaque. Nesse sentido, cita-se Gary Becker, realizando estudos que abordavam temáticas como o Direito de Família, o tráfico de drogas, crime e punição; Richard Posner e suas proposições abrangentes aos mais diversos campos do Direito em especial defendendo que "na ausência de qualquer teoria do valor operacionalizável e consensual, haveria justificativas éticas para se adotar a maximização da riqueza social como critério normativo, pois ela funcionaria como uma forma de aproximação da busca pela eficiência" (GICO JR., p.20); e, George Joseph Stigler e seus escritos sobre a desregulamentação da economia por parte do Estado. Nesse ínterim, observou-se, ainda, a difusão da experiência político-econômica neoliberal, destacando-se Friedrich Hayek (1960) e Milton Friedman (1962), dentre outros trabalhos, com a abordagem do fim do monopólio 
estatal sobre determinados serviços que poderiam passar a ser executados de forma mais efetiva e eficiente pela iniciativa privada.

Outra vertente que trabalha a AED é denominada Teoria da Escolha Pública (também chamada de Teoria da Eleição Pública). Sua principal característica é elaborar prognósticos fazendo-se valer dos mais variados recursos da Ciência Econômica para auxiliar a tomada de decisões na esfera política e administrativa. Fernando Araújo (2008, p. 60) lembra exemplos em que pode ser aplicada a Teoria em análise: a disputa entre a proteção dos direitos e a eficiência das políticas econômicas; o ciclo político-eleitoral e as motivações partidárias; e, o impacto econômico das integrações políticas e das soluções federais. Assim, para a Public Choice, a res pública deve ser otimizada segundo tomada de decisão política tal como deveria ocorrer na administração privada de bens e serviços. Não se pode desperdiçar erário público que deve ser tratado com a mesma diligência que se administram os bens e serviços privados.

No que diz respeito à escola Neoinstitucionalista, colaciona-se a definição verificada no The Ronald Coase Institute (2016).

\begin{abstract}
A Economia Neoinstitucional incorpora a teoria das instituições - leis, regras, costumes e normas - à economia. Calcada, modificada e extensível à teoria neoclássica. Essa mantém e constrói, sob o fundamento da escassez, e, consequentemente, da concorrência - a abordagem escolhida que se fundamente na Microeconomia. Ela foi desenvolvida como movimento das Ciências Sociais que une a pesquisa teórica à pesquisa empírica visando à análise do papel das instituições na promoção ou prevenção do crescimento econômico. Nela incluem-se os trabalhos sobre custos de transação, economia política, Direito de Propriedade, hierarquia e organização da eleição pública. Trata-se de trabalho em Ciência Política, Direito, Sociologia, Antropologia e outras Ciências Sociais.
\end{abstract}

Destarte, verifica-se que a Análise Econômica do Direito aprimorou-se ao longo dos anos para tentar analisar os trade off que surgem no quotidiano, através de análise consequencialista, no intuito de buscar a escolha mais eficaz ou, mesmo, eficiente e racional.

Contudo, reafirmando a análise epistemológica da sociedade elaborada por Niklas Luhmann (2005), é patente que a AED é passível de críticas por deixar de analisar determinados fenômenos sociais relevantes ou deixar de relevar variáveis outras, para além das econômicas, na tomada de decisão jurídico-política. É nesse ensejo que se passará a explanar específicas-críticas à referida matriz teórica. 


\section{Lineamentos em torno do critério da eficiência}

Para fazer-se valer da aplicação da Análise Econômica do Direito torna-se necessário entender que a Ciência Econômica, em sua teoria, divide-se em Macro e Microeconomia, interessando, para aquela, essa última. Em termos específicos, a Microeconomia consiste na análise das decisões tomadas pelos indivíduos (produtores e consumidores) ou por setores da economia (produtores - indústria, ou consumidores - coletivamente) ou grupos inerentes à sociedade, como as famílias e as empresas. Dentre vários elementos teóricos advindos da Microeconomia destaca-se a definição de eficiência.

Saber qual decisão é eficiente em determinado contexto jurídico é uma das principais finalidades da AED e por isso é relevante tecer críticas a essa valoração de um critério de justiça eficiente. No âmbito do Direito, de forma mais estrita, verifica-se a inclusão, por meio da Emenda Constitucional nº 19, de 04 de junho de 1998, do Princípio da Eficiência no Artigo 37 da Constituição da República Federativa do Brasil de 1988 (CRFB/88). Percebe-se, portanto, que o critério da eficiência passou a vigorar como diretriz para toda a administração pública, exigindo resultados satisfatórios para a 'máquina pública', bem como para a sociedade.

A primeira crítica que se pode fazer em relação à eficiência e sua definição é a polissemia que circunda o conceito de eficiência. Miguel Moura e Silva (2008, p. 24-27), por exemplo, cita três conceitos distintos de eficiência.

a) Eficiência na afetação de recursos: A noção mais clássica de eficiência reporta-se à afetação de recursos à utilização de maior valor.

b) Eficiência produtiva: [...] reporta-se estritamente à função (de) produção.

c) Eficiência dinâmica: [Consiste] na existência de restrições da concorrência que, induzindo uma aparente ineficiência na afetação de recursos (e.g. não permitindo que a quantidade produzida seja idêntica à que, a preços concorrenciais, seria consumida) $[\ldots]$.

A preocupação com a eficiência sempre esteve presente junto às empresas privadas e, a partir do Século XX, começou a permear na administração pública em geral, em um questionamento das práticas do Welfare-State. Cooter e Ulen (2012, p. 4) “defendem que um bom sistema legal mantém a rentabilidade dos negócios e o bem estar das pessoas alinhadas, assim, então, a busca do lucro também beneficia o público". Ocorre que o Estado Democrático de Direito hodierno não pode atentar tão somente a critérios quantitativos, devendo-se preocupar com outras dimensões de direitos que devem, também, ser analisados pela ótica da eficiência. 
Quando se fala de eficiência na Ciência Econômica, destacam-se dois arranjos teóricos: o primeiro foi proposto por Vilfredo Pareto e o segundo pelos economistas Nicholas Kaldor e John Hichs. No modelo desenvolvido por Pareto procura-se a alocação de recursos que apresente os maiores benefícios para o agente sem prejudicar terceiros. Essa situação é conhecida como Ótimo de Pareto. Por seu turno, a eficiência em Kaldor-Hicks é entendida como maximização da melhora desejada a ponto de que, em havendo prejuízos para terceiros, haverá a possibilidade de reparação ou compensação do dano.

A seu turno, é de ser lembrado, também, o Princípio da Eficiência Econômico-Social (PEES) (GONÇALVES; STELZER, 2016a) que atribui limite na tomada de decisão que afete a sociedade, visando respeitar o Mínimo Ético Legal (MEL) estipulado pelo Estado. Faz-se mister salientar que o papel do Estado, em relação à sociedade, mudou com o passar do tempo: no Século XIX, o Estado garantia somente as liberdades individuais; do final do Século XIX até a primeira metade do Século XX, prevaleceram os direitos sociais; da segunda metade do Século XX até o presente momento, o Estado somou aos demais direitos a questão da fraternidade. Dessa forma, percebe-se que as teorias jurídicas não podem deixar de cumprir as determinações que alicerçam o Estado Democrático de Direito.

A aplicação do Direito de forma eficiente e que leve em consideração as questões sociais visando diminuir ao máximo as externalidades negativas acaba por ter como principal objetivo atingir critério de justiça, no qual a tomada de decisão observe os preceitos inerentes ao PEES, tendo como exemplo o primado da distribuição e redistribuição dos escassos recursos em função da eficiência econômico-social, segundo o Mínimo Ético Legal determinado pelo Estado e a avaliação dos resultados do sistema jurídico e de sua concreta aplicação a partir da "consideração dos incentivos indutores ou obstantes da ação social" (GONÇALVES; STELZER, 2016a, p. 275).

\subsection{Comércio Internacional: justiça ou eficiência para o free trade?}

Nos países que adotam a socialdemocracia a aplicação da Análise Econômica do Direito torna-se interessante a partir da observância do Princípio da Eficiência EconômicoSocial. Não obstante, as relações entre os Estados também deveriam obedecer tais critérios. No presente trabalho objetiva-se ater à questão do comércio internacional. Assim, questionase quanto à necessidade de ser implementada, na agenda internacional, prática inclusora de comércio que, para além de justo, deve ser eficiente. 
Inicialmente, devem ser lembradas iniciativas de grande respaldo quanto ao aspecto de justiça social, contudo, por sua ineficiência acabaram tendo pífios resultados. Assim, citese o Sistema Geral de Preferências (SGP) criado na Conferência das Nações Unidas para o Comércio e Desenvolvimento (UNCTAD), então sob a idealização da lógica cepalina e sob influência do economista argentino Raul Prebisch. A ideia era que as mercadorias de países em desenvolvimento pudessem ter um acesso privilegiado aos mercados dos países desenvolvidos, em bases não recíprocas. Superar-se-ia o problema da deterioração dos termos de troca e haveria a facilitação do avanço dos países beneficiados nas etapas no processo de desenvolvimento (MDIC, 2016).

Sob tal aspecto, embora diversos produtos tenham sido incluídos na pauta exportadora brasileira, não há informações quanto à inclusão de pequenos produtores. Em que pese a existência de alguns benefícios, o SGP não foi capaz de impulsionar o Brasil da sua $27^{\circ}$ posição exportadora mundial, dados da OMC indicam que ao final de 2015 a participação brasileira no volume exportado mundialmente foi de 1\%. (WTO, 2016). Apesar do ímpeto de justiça comercial internacional o SGP, nem do ponto de vista externo, nem por intermédio de políticas públicas internas, permitiu o avanço comercial exportador brasileiro. Quanto à inclusão social do pequeno produtor, esse sequer foi um tema tocado pelo SGP. Em verdade, o SGP não mexe nas estruturas do comércio internacional, não altera a compreensão sobre o que é eficiência, motivo pelo qual não pode desejar colher resultados outros que não sejam a manutenção do perverso sistema.

O comércio internacional entendido como Free Trade tem como principal suporte normativo o Acordo Geral de Tarifas e Comércio (denominado General Agreement on Tariffs and Trade - GATT/47; hoje, GATT/94) e a Organização Mundial do Comércio (OMC), cujo objetivo é mitigar as barreiras alfandegárias e não alfandegárias para facilitar a troca de mercadorias entre os países signatários do Acordo Geral.

Países mais eficientes do ponto de vista econômico são encorajados a participar, pois esse é o mote do sistema: 'ao vencedor, as batatas'. Desnuda-se o ser humano, que vença o mais forte, pois aspectos de sustentabilidade não entram nesse debate.

É bem verdade que o GATT/1994 possui normas que visam à proteção e à garantia de prerrogativas para os países não desenvolvidos e em relativo desenvolvimento, prometendo mínima inclusão social. Contudo, na prática, há uma discrepância conspícua em relação ao tratamento dado aos países que buscam participar do sistema. Há décadas, assiste-se o aumento dos ganhos de países centrais em detrimento dos menos favorecidos. O livre câmbio, 
em verdade, encobre o protecionismo dos poderosos, que fazem regras à semelhança das suas possibilidades e forças. Afinal, a mundialização é uma modalidade de funcionamento do capitalismo na qual os ricos ficam mais ricos e os pobres ficam mais pobres. (REICH, 2008)

Como se percebe, a interpretação economicista pautada exclusivamente pela eficiência gera concentração de exportação e manutenção do status quo. Por outro lado, o ideal de justiça tomado isoladamente ou por regras sem reciprocidade, como o SGP, acarretam a inoperância dos operadores que, ao perderem o poder de barganha, deixam ao alvedrio a possibilidade de manutenção das listas de produtos. Nessas situações, modo geral, em virtude da própria conjuntura econômica, os países centrais sentem-se mais ou menos estimulados a distribuir benefícios. Os países periféricos ficam em compasso de espera.

Frente a tais dificuldades, defende-se o Princípio da Eficiência Econômico-Social na qualidade de ferramenta teórica e de matriz metodológica que traz à tona o 'ponto cego' do livre comércio internacional (Free Trade), uma vez que auxilia na conciliação dos interesses dos grandes agentes econômicos com os interesses da coletividade. A aplicação do PEES revela inúmeras variáveis desconsideradas no modelo tradicional do livre comércio. Ladislau Dowbor (2010, p. 18) ressalta a "necessidade de se evoluir para uma contabilidade que explicite o resultado em termos de qualidade de vida, de progresso social real". Passa-se então a dar atenção para elementos como a responsabilidade socioambiental no processo de produção, a necessidade de combate ao trabalho escravo (semi-escravo ou sob condições indignas), a premência em estabelecer igualdade de gênero, o combate ao trabalho infantil, entre tantas outras situações vergonhosas que maculam grande quantidade de produtos utilizado no cotidiano da sociedade. Um dos mais emblemáticos exemplos refere-se à Corporação Foxconn, exportadora chinesa de iPhones, acusada de levar funcionários ao suicídio por jornadas de trabalho extenuantes. Tal método de relação empregatícia possui eficiência econômica à medida que diminui custos, mas às custas da dignidade humana e do direito à vida. Enquanto os produtos se beneficiam de um baixo custo (com aumento da competitividade) e o mercado de smartphones é conquistado, a externalidade negativa assombra a existência do humano por trás do chip e do componente eletrônico. A solução para o problema foi rasa: os prédios da fábrica receberam redes de segurança para impedir que os funcionários morram ao se jogarem dos edifícios.(TECNOBLOG, 2016)

É justamente com a identificação das externalidades negativas que emerge o Princípio da Eficiência Econômico-Social na qualidade de possível vetor a reger o comércio externo, de maneira que se possa transitar do Free Trade para o Fair Trade. Afinal, a mera 
observância de um único critério, vale dizer, o auferimento de lucro, reduz de maneira significativa as variáveis que compõem o cálculo econométrico. Segundo o PEES, a considerar o surgimento de inúmeras externalidades negativas que afetam diretamente terceiros e, ao longo prazo, também afetarão os próprios agentes econômicos envolvidos na tomada de decisão econômico-jurídica, a sociedade internacional caminha para seu próprio extermínio. Até que ponto, a concentração de renda, a destruição ambiental, o descaso na relação empregatícia, entre outros, serão suportáveis pela sociedade internacional. O fomento de outras modalidades de comércio, nas quais haja a minimização do dano, acaba por se impor. É nesse ensejo que surge o Comércio Justo.

\subsection{Fair Trade Internacional e a aplicação do Princípio da Eficiência Econômico-Social}

O movimento por um Comércio Justo pode ter tido início nos Estados Unidos, na década de 1940, no qual consumidores começaram a importar bordados de Porto Rico, dando preferência ao produto de um país periférico. Na Europa iniciava-se o consumo ético com as denominadas Organizações de Comércio Alternativo (1946), a Fair Trade Organisatie (1967) e a Global Exchange (1988). Em 1988 foi estabelecida a certificadora Holandesa Max Havelaar, e o primeiro produto certificado foi o café produzido pelas Comunidades Indígenas de la Region de Isthmus (UCIRI) (LEVI; LINTON, 2016).

Os esforços pela promoção do Fair Trade no continente europeu também foram liderados pela Oxfam e por um grupo católico holandês. A Oxfam International é uma organização com mais de 3000 parceiros na atualidade, sempre visando às alternativas que tragam resultados para o dilema da pobreza e da injustiça.

A Organização Mundial do Comércio Justo define essa nova modalidade de comércio como sendo uma "parceria comercial, baseada no diálogo, transparência e respeito, que busca maior equidade no comércio internacional, cooperando para o desenvolvimento sustentável e garantindo os direitos dos produtores e trabalhadores marginalizados”. (WFTO, 2016a)

O Comércio Justo possui substancial esforço para articular diversas operações, como importar, distribuir e comercializar produtos de organizações preocupadas com os produtores (mas, não exclusivamente), com destaque àqueles oriundos de países em desenvolvimento. $\mathrm{O}$ foco está em alterar injustas estruturas do comércio mundial, como a influência de poucas corporações transnacionais e subsídios públicos por governos oriundos de países tidos por 
centrais, especialmente no comércio agrícola. No âmbito do Comércio Justo também outros sujeitos que intervém na cadeia comercial são incluídos: exportadores, importadores, transportadores, transformadores, distribuidoras, poderes públicos, organizações sindicais, entre outros. Almeja-se sustentabilidade econômico-social por toda a cadeia.

Sob tal vetor, ter-se-ia uma mudança de paradigma, no qual o lucro deixa de ser o elemento exclusivo do comércio internacional tradicional ou, entendido de outro modo, na qual as externalidades negativas do Free Trade passam a compor o cálculo econométrico. $\mathrm{O}$ Comércio Justo atua como importante ferramenta para modificar a realidade social nas periferias do capitalismo, acarretando o empoderamento dos produtores e das comunidades aos quais pertencem. Vale dizer, não se utiliza o critério de eficiência econômica como única ferramenta de cálculo.

No intuito de orientar como deve ser a prática do Comércio Justo, a Organização Mundial do Comércio Justo (WFTO, 2016b) elaborou dez diretrizes que balizam sua atuação e organização:

1) Criação de oportunidades para produtores em desvantagem econômica; 2) Transparência e responsabilidade administrativa; 3) Práticas de Comércio Justo; 4) Preço justo; 5) Inexistência de trabalho infantil ou trabalhos forçados; 6) Compromisso de não discriminação, igualdade de gênero, emponderamento econômico das mulheres e liberdade de associação; 7) Condições dignas de trabalho; 8) Desenvolvimento das capacidades laborais; 9) Promoção do Comércio Justo; 10) Respeito ao meio ambiente.

Mesmo apresentando-se como efetiva possibilidade de mudança para a vida de uma quantidade significativa de pessoas, a implementação do Comércio Justo ainda encontra elementos que impossibilitam e dificultam a sua aplicação. Os principais óbices consistem: primeiro, na mudança do paradigma do consumo (e do consumismo) e; segundo, na aceitação do critério de sustentabilidade na inclusão do cálculo econométrico.

Com efeito, enquanto o consumo constitui uma característica e ocupação de todos os seres humanos enquanto indivíduos, o consumismo é um "atributo da sociedade" (BAUMAN, 2008, p. 42). Para o autor, o 'consumismo' se realiza quando o consumo assume o papelchave que na sociedade de produtores era exercido pelo trabalho. Dessa maneira, o consumismo passa a ser central quando:

[...] a capacidade profundamente individual de querer, desejar e almejar deve ser, tal como a capacidade de trabalho na sociedade de produtores, destacada ('alienada', o termo aqui empregado não em conotação pejorativa) dos indivíduos e reciclada/reificada numa força externa que coloca a 'sociedade de consumidores' em movimento e a mantém em curso como uma forma específica de convívio humano, 
enquanto ao mesmo tempo estabelece parâmetros específicos para as estratégias individuais de vida que são eficazes e manipula as probabilidades de escolha e conduta individuais. (BAUMAN, 2008, p. 42).

Gilles Lipovetsky (2007) caminha em semelhante sentido, mencionando o consumo doentio como 'felicidade paradoxal', efêmera, que se finda ao término do próprio consumo. $\mathrm{O}$ consumidor, dessa maneira, jamais se sente satisfeito e sempre almejará novos produtos. Esses, por sua vez, não assumirão a forma de objetos apenas, mas, experiências, emoções e sensações. Com isso, impõe-se a conclusão do Banco Mundial que serão necessários quase três planetas Terra para proporcionar os recursos naturais necessários a fim de manter o atual estilo de vida da humanidade, caso a população global chegue a 9,6 bilhões em 2050. "Outro dado preocupante é que cerca de 200 milhões de pessoas podem ser afetadas pelos resíduos presentes em 3000 locais em todo o mundo." (THE WORLD BANK, 2016).

Esses são aspectos decisivos quando se questiona a possibilidade de mudança paradigmática de livre comércio (Free Trade) para comércio com justiça (Fair Trade). Hanna Arendt é mais enfática quando sustenta que as próprias pessoas findam por ser pensadas como objetos a serem consumidos, calculados e programados.

[...] Mas, se esse ideal já estivesse realizado e passássemos realmente de membros de uma sociedade de consumidores, já não viveríamos mais num mundo, mas, simplesmente seríamos impelidos por um processo em cujos ciclos - perenemente repetidos - as coisas surgem e desaparecem, manifestam-se e somem, sem jamais durar o tempo suficiente para conterem em seu meio o processo vital. (ARENDT, 2010, p.147)

Finalmente, por proporcionar condições mais dignas aos trabalhadores no processo de produção, uma vez que garante salários justos, qualificação da mão de obra, meios de preservação do meio ambiente, dentre outros, os custos de produção podem findar por serem mais elevados para produtos de Comércio Justo com relação ao Free Trade. Afinal, esse modelo resulta por atribuir a externalidade negativa à coletividade ao longo do tempo, de maneira que os nefastos resultados não sejam percebidos imediatamente. Contudo, que fique expresso: a aparente oneração dos produtos e serviços de Comércio Justo é, na verdade, uma forma de otimização das externalidades positivas. Os custos para a preservação do ambiente que são agregados ao produto final, por exemplo, são mais baratos do que custear uma política emergencial para limpeza de rios e reflorestamento; ou, tratamento hospitalar para remediar problemas respiratórios resultantes da poluição atmosférica. Essa é a forçosa conclusão da Análise Econômica do Direito e do Princípio da Eficiência Econômico-Social. 
Uma sociedade que se quer justa deve planejar uma concepção pública de justiça para promover o bem-estar de seus membros. Para alcançar esse ideal, é preciso estabelecer uma estrutura básica, de modo a permitir que as instituições sociais mais importantes distribuam os direitos e deveres fundamentais. Johns Rawls esclarece que uma concepção de justiça social deve fornecer primeiramente um padrão pelo qual se devem avaliar os aspectos distributivos da estrutura básica da sociedade. Nesse sentido, adverte que a "distribuição natural não é justa nem injusta; nem é injusto que pessoas nasçam em alguma posição particular na sociedade. Esses são simplesmente fatos naturais. O que é justo ou injusto é o modo como as instituições lidam com esses fatos." (RAWLS, 1997, p. 1090)

Se os homens são desiguais, contudo, não é preciso conformar-se resignadamente, porque o sistema social é passível de alteração, mas será preciso uma mudança de mentalidade. Do comportamento individual, em especial dos operadores de direito, será exigida uma postura crítica e reflexiva diante da alienação de massa, organizada pela lógica do mercado. Será necessário situar o processo econômico e social dentro de um contexto de instituições políticas e jurídicas adequadas. Necessita-se, pois, de uma reorganização da sociedade, de modo a viabilizar um processo distributivo justo. Essa é a proposta de um critério de eficiência econômico-social (PEES). (GONÇALVES; STELZER, 2016b)

Por se tratar de reformulação estrutural do sistema comercial internacional, é preciso recontextualizar o ambiente social, aliás, profundamente alterado pela globalização econômica. Se a guerra pode ser territorial, também pode ser econômica. Se o direito já foi expressamente reservado a determinadas camadas da sociedade, enquanto outras classes eram excluídas (como a dos escravos), hoje a exclusão é simplesmente tácita. Mais do que nunca, é preciso estar bem consciente dessa nova concepção de mundo para não soçobrar na desconexão normativa do direito com a vida.

Em meio à interdisciplinariedade da práxis jurídico-legal, há uma possibilidade interessante por parte da Análise Econômica do Direito que se estrutura, ora como método interpretativo, ora como inerente à natureza economicista do próprio Direito. Em tempos de globalização, sob ótica economicista neoliberalizante vigente dentro do sistema capitalista abrangente, há muitos países alinhados em transações comerciais, em intercâmbio de culturas e em aproximações institucionais, sem a necessária postura crítica. Emerge, portanto, evidente, entender a lógica econômico-juridicista que, inquestionavelmente, está inserida na práxis de governos e no ordenamento do comércio liberalizante, situação na qual se defende a metodologia do PEES como vetor para a tomada de decisões. 


\section{CONCLUSÃO}

As escolhas oriundas das tomadas de decisões acarretam consequências que, a depender do referencial teórico, podem ser parcialmente previstas e incluídas no cálculo econométrico. A Análise Econômica do Direito surge para elaborar diagnósticos e prognósticos, a partir de abordagens pertencentes à seara da Ciência Econômica, sobre as consequências decorrentes de determinadas escolhas relacionadas ao mundo do Direito.

Sabendo-se que toda observação de fenômeno social é parcial, verificou-se que a Análise Econômica do Direito deve atentar para variáveis que são muito relevantes para o Estado Democrático de Direito, como, por exemplo, as questões socioambientais. Visando complementar as lacunas de tal matriz teórica, o Princípio da Eficiência Econômico-Social (PEES) elucida as questões que a perspectiva pautada unicamente no critério da eficiência ignora.

Ao analisar a organização do comércio internacional, capitaneada pela Organização Mundial do Comércio e regida pelo Acordo Geral de Tarifas e Comércio, constatou-se, por intermédio do Princípio da Eficiência Econômico-Social, que o modelo de Free Trade, cujo principal objetivo é o lucro, resulta em várias externalidades negativas que atingem, inclusive, os terceiros não envolvidos diretamente no processo de produção, exportação, importação e consumo; ainda, não levando em consideração quaisquer medidas disjuntivas.

Propõe-se, dessa forma, o fomento ao Fair Trade como alternativa ao comércio internacional, que tem como principal finalidade atenuar as externalidades de um sistema de troca supostamente livre, tendo em vista que esse novo modelo preocupa-se com o pagamento de preço justo aos produtores, à preservação do meio-ambiente e à transparência na cadeia de produção, o que resulta numa busca pela justiça social.

Mesmo com as dificuldades para a implementação do Comércio Justo, os Estados Democráticos de Direito têm a obrigação de promover o seu fomento para tentar mudar as regras do tradicional comércio internacional, buscando a redução das desigualdades sociais, favorecendo o desenvolvimento sustentável e a inclusão social para que, ao fim de tudo, possa-se chegar ao ideal que pauta a sociedade e o Estado contemporâneo: a fraternidade, ainda, em ação pautada pelo PEES. 


\section{REFERÊNCIAS}

ARAÚJO, Fernando. Análise Económica do Direito: Programa e Guia de Estudo. Lisboa: Almedina, 2008.

ARENDT, Hanna. A Condição Humana. Tradução de Roberto Raposo. 11.ed. Rio de Janeiro: Forense Universitária, 2010.

BAUMAN, Zygmunt. Vida para o Consumo: a transformação das pessoas em mercadorias. Rio de Janeiro: Zahar, 2008.

BRASIL. Emenda Constitucional no 19, de 04 de junho de 1998. Modifica o regime e dispõe sobre princípios e normas da Administração Pública, servidores e agentes políticos, controle de despesas e finanças públicas e custeio de atividades a cargo do Distrito Federal, e dá outras providências.Brasília, Disponível em:

http://www.planalto.gov.br/ccivil_03/Constituicao/Emendas/Emc/emc19.htm. Acesso em: 02 ago. 2016.

COASE, Ronald. The Problem of Social Cost. Law And Economics Journal. Chicago, p. 144. out. 1960. Disponível em:

http://econ.ucsb.edu/ tedb/Courses/UCSBpf/readings/coase.pdf. Acesso em: 02 ago. 2016.

COOTER, Robert; ULEN, Thomas. Law and Economics. Boston: Pearson, 2012.

DISPUTE SETTEMENT (WORLD TRADE ORGANIZATION). India - Quantitative Restrictions on Imports of Agricultural, Textile and Industrial Products. Disponível em: https://www.wto.org/english/tratop_e/dispu_e/cases_e/ds90_e.htm. Acesso em: 03 ago. 2016.

DOWBOR, Ladislau. Democracia Econômica: um passeio pelas teorias. Fortaleza: Banco do Nordeste do Brasil, 2010.

GICO JÚNIOR, Ivo T. Metodologia e Epistemologia da Análise Econômica do Direito. Economics Analysis Of Law Review, [s. 1.], v. 1, n. 1, p.7-32, jan. 6.

GONÇALVES, Everton das Neves; STELZER, Joana. Princípio da Eficiência EconômicoSocial no Direito Brasileiro: a tomada de decisão normativo-judicial. Sequência: Estudos Jurídicos e Políticos, Florianópolis, v. 35, n. 68, p.261-290, 20 jun. 2014. Universidade Federal de Santa Catarina (UFSC). http://dx.doi.org/10.5007/2177-7055.2013v35n68p261. Disponível em: https://periodicos.ufsc.br/index.php/sequencia/article/view/21777055.2013v35n68p261. Acesso em: 02 ago. 2016a.

GONÇALVES, Everton das Neves; STELZER, Joana. A ação empresarial e o Estado: o consenso ético como alternativa à discussão de controle entre a esfera privada e a Administração Pública. Disponível em: http://www.publicadireito.com.br/artigos/?cod=4a47d2983c8bd392. Acesso em: 09 ago. $2016 b$. 
HABERMAS, Jürgen. Direito e Democracia: Entre facticidade e validade. Tradução de Flávio Beno Siebeneichler. Rio de Janeiro: Tempo Brasileiro, 1997.

LEVI, M.; LINTON, A. Fair Trade: A Cup at a Time?. Disponível em:

http://fsi.stanford.edu/sites/default/files/Levi.pdf Acesso em: 2 set. 2016.

LIPOVETSKY, Gilles. A felicidade paradoxal: ensaio sobre uma sociedade de hiperconsumo. São Paulo: Companhia das Letras, 2007.

LUHMANN, Niklas. EI Derecho de la Sociedad. Tradução de Javier Torres Nafarrate. Ciudad de Mexico: Hedra/Universidad Iberoamericana, 2005.

MDIC (Ministério do Desenvolvimento, Indústria e Comércio Exterior). Sistema Geral de Preferências. Disponível em:

http://www.desenvolvimento.gov.br/sitio/interna/interna.php?area=5\&menu=407. Acesso em: 25 ago. 2016.

MORDFIN, Robin I.; NAGORSKY, Marsha Ferziger. Chicago and Law and Economics: A History. Disponível em: http://www.law.uchicago.edu/alumni/magazine/fall11/lawandeconhistory. Acesso em: 02 ago. 2016.

OXFAM. What we do. Disponível em: <http://www.oxfam.org.uk/> Acesso em: 12 ago. 2016.

PASSOS FILHO, Paulo. A exclusão do Brasil do SGP europeu e seus impactos sobre a fruticultura de exportação. Disponível em:

http://www.barralmjorge.com.br/arquivos/pontes11-2.pdf . Acesso em: 26 ago. 2016.

POSNER, Richard. Economic Analisis of Law. Boston: Little Brown and Company, 1992.

RAWLS, John. Uma teoria da justiça. Tradução de Almiro Pisetta e Lenita M. R. Esteves. São Paulo: Martins Fontes, 1997.

REICH, Robert B. Supercapitalismo: como o capitalismo tem transformado os negócios, a democracia e o cotidiano. Rio de Janeiro: Campus-Elsevier, 2008.

SCHMITT, Carl. O Guardião da Constituição. Tradução de Geraldo de Carvalho. Belo Horizonte: Del Rey, 2007.

SILVA, Miguel Moura e. Direito da Concorrência: uma introdução jurisprudencial. Coimbra: Almedina, 2008.

SMITH, Adam. A Riqueza das Nações: Investigação sobre a natureza e suas causas. São Paulo: Nova Cultural, 1996.

SZTAJN, Rachel. Law and Economics. In: ZYLBERSZTAJN, Decio; SZTAJN, Rachel. Direito \& Economia: Análise Econômica do Direito e das Organizações. Rio de Janeiro: Elsevier, 2005. p. 80-87. 
TECNOBLOG. Foxconn instala redes para impedir suicídios. Disponível em: https://tecnoblog.net/28972/foxconn-instala-redes-para-impedir-suicidios/ Acesso em: 2 set. 2016.

THE RONALD COASE INSTITUTE. About New Institutional Economics. Disponível em: https://www.coase.org/newinstitutionaleconomics.htm. Acesso em: 03 ago. 2016.

THE WORLD BANK. Vamos mesmo precisar de dois novos planetas? Disponível em: http://www.worldbank.org/pt/news/feature/2016/08/09/objetivo-desarrollo-sostenible-ods-12consumo Acesso em: 2 set. 2016.

WORLD FAIR TRADE ORGANIZATION. Definition of Fair Trade. Disponível em: http://www.wfto.com/fair-trade/definition-fair-trade. Acesso em: 03 ago. 2016a.

10 Principles of Fair Trade. Disponível em: http://www.wfto.com/fairtrade/10-principles-fair-trade. Acesso em: 03 ago. 2016b.

WTO (WORLD TRADE ORGANIZATION). To Doha and beyond: a roadmap for successfully concluding the Doha Development Round. Evian VII Plenary Meeting 'A Second Wind for the 3rd Millennium: Post-Doha Global Economic Agenda'. Disponível em: https://www.wto.org/english/news_e/spmm_e/spmm83_e.htm. Acesso em: 03 ago. 2016. 